\title{
Improving the port selection process during military deployments
}

\author{
Dave C. Longhorn, Joshua R. Muckensturm and Shelby V. Baybordi \\ JDPAC, US Transportation Command, Belleville, Illinois, USA
}

Abstract

Purpose - This paper recommends new criteria for selecting seaports of embarkation during military deployments. Most importantly, this research compares the current port selection criterion, which is to select the seaport with the shortest inland transport time from the deploying installation, to the proposed port selection criteria, which are to select the seaport based on the shortest combined inland and oceanic transit time to the destination theater.

Design/methodology/approach - The authors construct an original integer program to select seaports that minimize the expected delivery timeline for a set of notional, but realistic, deployment requirements. The integer program is solved considering the current as well as the proposed port selection criteria. The solutions are then compared using paired-samples $t$-tests to assess the statistical significance of the port selection criteria. Findings - This work suggests that the current port selection criterion results in a 10-13\% slower delivery of deploying forces as compared to the proposed port selection criteria.

Research limitations/implications - This work assumes deterministic inland transit times, oceanic transit times, and seaport processing rates. Operational fluctuations in transit times and processing rates are not expected to change the findings from this research.

Practical implications - This research provides evidence that the current port selection criterion for selecting seaports for military units deploying from the Continental United States is suboptimal. More importantly, logistics planners could use these recommended port selection criteria to reduce the expected delivery timelines during military deployments.

Originality/value - Several military doctrinal references suggest that planners select seaports based on habitual installation-to-port pairings, especially for early deployers. This work recommends a change to the military's current port selection process based on empirical analyses that show improvements to deployment timelines.

Keywords Port choice, Port selection factors, Military logistics, Integer programming, Paired-samples $t$-test Paper type Research paper

\section{Introduction}

The United States (US) military deploys large amounts of equipment to overseas locations during times of war. The US Joint Chiefs of Staff (2013b) notes that about $90 \%$ of the equipment deploying from the Continental US (CONUS) is transported by roll-on/roll-off (RORO) sealift ships. Sealift is the preferred mode to transport large amounts of heavy equipment, although airlift can transport small amounts of equipment anywhere in the world within a few days (US Joint Chiefs of Staff, 2013b). The equipment is loaded onto RORO ships at the CONUS strategic seaports, which are primarily commercially owned. The infrastructure at strategic seaports is heavily leveraged to support global deployment operations (US Joint Chiefs of Staff, 2013b), and each of the ten primary seaports has different attributes, such as geographic location, number of shipping berths, berth length and depth, cargo staging area, and cargo reception and processing rates. Furthermore, the seaports can

(C) In accordance with section 105 of the US Copyright Act, this work has been produced by a US government employee and shall be considered a public domain work, as copyright protection is not available. Published in Journal of Defense Analytics and Logistics. Published by Emerald Publishing Limited.

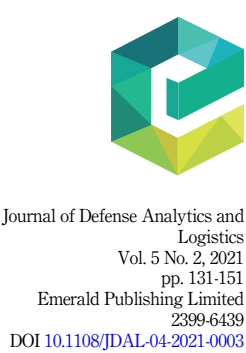


JDAL 5,2

become congested during wartime deployments because numerous military units deploy through the ports in a relatively short timeframe. As such, selecting the best seaports through which military units deploy is an important logistics problem. US Transportation Command analysts informally call this problem the Military Port Selection Problem (MPSP), which is the focus of this research paper.

The MPSP is a variant of port choice problems, which have been studied extensively by academia and industry. Several key differences exist between the MPSP and previous port choice problems. First, the MPSP involves selecting ports that handle RORO ships, whereas port choice problems in industry are more commonly related to container ports (Hsu et al., 2020; Kaliszewski et al., 2020; Kolar and Rodrigue, 2018; Moya and Valero, 2017; Sayareh and Alizmii, 2014; Fan et al., 2012; Steven and Corsi, 2012; Yuen et al., 2012; Maloni and Jackson, 2005). Second, the desired outcome of selecting ports in the MPSP is to achieve the earliest expected arrival of military units at theater destinations, that is, delivery speed is the most important outcome. Conversely, the desired outcome of port selection in industry often involves cost-efficiency considerations (Baert and Reynaerts, 2020; Osundiran et al., 2020; Parola et al., 2017; Wu et al., 2014; Yuen et al., 2012; Tran, 2011).

Despite the differences between the MPSP and other port choice problems, our research reinforces a common theme from the port selection literature, namely that the importance of port selection criteria is based on one's perspective (Kramberger et al., 2018; Parola et al., 2017; Yuen et al., 2012; Sanchez et al., 2011; Murphy and Daley, 1994; Murphy et al., 1992). The differing perspectives most often cited in the literature are those of shippers, shipping companies (or carriers), and port authorities (or operators). The military deployer's perspective has not been explicitly addressed in the port selection literature; however, the military deployer's perspective with respect to port selection most closely aligns with that of large shippers who emphasize timeliness. In this way, our research adds the military deployer's perspective to the broader perspective of shippers.

Port selection decisions during major deployments are made by planners at the US Transportation Command (US Joint Chiefs of Staff, 2013b). The current port selection criterion is based on the shortest inland transit time from installation to port, which derives from a habitual installation-to-port pairing, that is, units from a certain installation are matched to a nearby port. As an example, units deploying from Fort Stewart, Georgia have a habitual port pairing with the Port of Savannah, Georgia. The current port selection criterion stems from several operational realities. First, the US must be prepared to deploy forces quickly to theater destinations either across the Atlantic Ocean (i.e. an east deployment) or across the Pacific Ocean (i.e. a west deployment). Sealift ships are positioned, or layberthed, near seaports on each of the CONUS coasts (East, Gulf, West) as part of a balanced ship positioning strategy to facilitate rapid delivery of "first wave" forces for either an east or west deployment (US Department of Transportation, 2021). The rationale is that first wave units located in the eastern CONUS should deploy through East coast ports, units in the central CONUS should deploy through Gulf coast ports and units in the western CONUS should deploy through West coast ports. This logic is codified in SDDCTEA Pamphlet 700-2 (2011), which specifies that ports are selected during deployments based on the closest port to deploying units, as well as in US Joint Chiefs of Staff (1996), which notes that the proximity of installations to ports is a key factor in port selection. Second, the relative closeness of each installation to its primary port allows, in some cases, deploying units to transport their equipment on its own cargo trucks thereby reducing its reliance on commercial railcars and trucks (US Joint Chiefs of Staff, 2013a). Finally, installations are required to conduct deployment exercises to maintain proficiency (US Joint Chiefs of Staff, 2013a) and these exercises are usually to and through habitual ports, in which units become familiar with the port's infrastructure layout and cargo processing policies (US Headquarters of the Army, 2015). 
For the reasons described above, the current port selection criterion of habitual installation-port pairings is logical and supported by established military doctrine. However, habitual port pairings as the sole port selection criterion may yield suboptimal solutions. For instance, using a different port might have a shorter total transit time, especially when considering the relatively long oceanic transit time from the selected port to theater. The habitual port may also receive too many units resulting in congestion due to constrained port capacities. The present research suggests that new port selection criteria based on the combined shortest inland and oceanic transit times would result in a faster overall delivery of first wave forces to theater destinations.

The overarching goal of our research is to improve the military's port selection process within the US Transportation Command. As such, the focus of this paper is to describe the MPSP, propose new port selection criteria for consideration, and assess the performance of the proposed criteria using mathematical programming with test data. Specifically, we introduce an integer program (IP) to optimize the assignment of deploying units to seaports. The IP objective function is key to assessing the importance of the proposed port selection criteria because we can solve the IP with different objective functions that explicitly consider one or more port selection criteria. The IP solutions thus provide us with unbiased estimates for the importance of the port selection criteria. To test solution robustness, we generate numerous large-scale deployment scenarios each with different outload requirements. Then, we conduct statistical tests of differences, namely paired-samples $t$-tests, to identify significant differences in expected arrival times in theater between the current and proposed port selection criteria. We report the results and discuss our findings in the context of other port selection problems. Finally, we suggest possible extensions to the present work for future researchers.

\section{Literature review}

Port selection criteria have been studied by industry and academia for over thirty years. Moya and Valero (2017), Parola et al. (2017), and Steven and Corsi (2012) provide thorough surveys of previous research related to port selection. The most prevalent port selection criteria from the literature, in no particular order, are geographical location, nautical accessibility, port infrastructure, port efficiency (e.g. turnaround and dwell times, cranes rates), harmony with port labor unions, quality of port services (i.e. customer service), and cost. Other port selection criteria have been reported as influential, but with less frequency. Table 1 provides our categorization of the most common port selection criteria and the researchers who reported one or more of the listed criteria as important.

Although the literature on port selection is diverse, researchers commonly suggest that perspective is key to understanding which port selection criteria are most important to decision makers. The perspectives of at least three entities have been identified by previous researchers: shippers (or freight forwarders), shipping companies (or carriers) and port authorities (or port operators). Researchers most often study port selection factors from a single perspective. In general, shippers tend to favor cost, location, nautical accessibility, and inland (or hinterland) access and connections as the most important port selection criteria (Steven and Corsi, 2012; Yuen et al., 2012; Tran, 2011; Tongzon, 2009; Murphy and Daley, 1994). Key port selection criteria from a shipping company's perspective seem to favor profits and economies of scale (Hsu et al., 2020; Yuen et al., 2012; Tang et al., 2011; Malchow and Kanafani, 2004). Finally, port authorities are most concerned with port selection criteria within their control, such as port infrastructure, port efficiency and labor relations (Osundiran et al., 2020; Murphy and Daley, 1994).

The perspective of our MPSP most closely aligns with that of a shipper, because deploying military units neither profit from the port decision nor do they control the commercial ports.
Improving the port selection process 


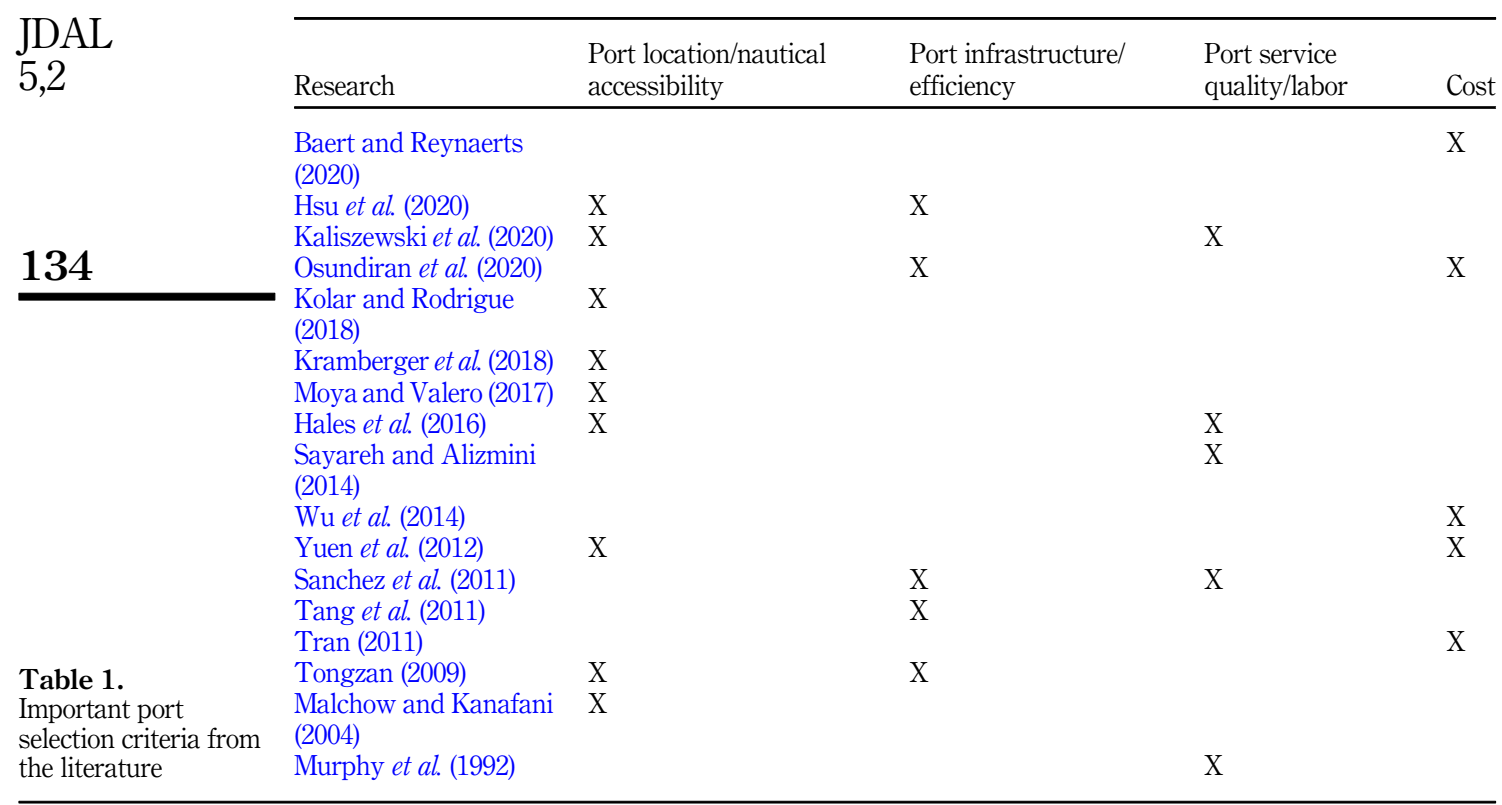

As such, our hypothesis is that the important criteria in the MPSP are likely similar to those considered by other shippers, that is, criteria related to cost, geographic location and accessibility as described herein. Military deployers could be considered large shippers during a major deployment due to the immense amount of cargo deployed, for example, US Government Accountability Office (2005) reports that OPERATION Iraqi Freedom involved deploying over two million tons of unit equipment and cargo. Steven and Corsi (2012) concluded that large shippers are more sensitive to the criteria that enable faster delivery than to criteria related to monetary costs. Similarly, military units are generally not concerned with monetary costs during a major deployment. However, any delays in a unit's deployment have an inherent operational cost that should be minimized to enable rapid mobility (US Joint Chiefs of Staff, 2013a). Related to the notion of time and associated delays is the fact that the geographical location of a selected seaport influences two time-related factors, namely the inland transit time from an installation and the oceanic transit time to a theater destination. Furthermore, too much equipment sent through a seaport could likewise cause delays due to congestion. Additionally, sealift ships may not be immediately available at a seaport to commence onloading operations, which could also cause delays. As such, the present research captures both port congestion and sealift ship availability.

\section{Methods}

Formally, the MPSP is to assign units deploying in the first wave to seaports given the following considerations:

(1) the amount of unit equipment outloading from installations to theater destinations;

(2) the inland transport time from installation to the selected seaport;

(3) the daily throughput capacity at the selected seaport; 
(4) the activation and sail time of sealift ships to reach the selected seaport from layberth locations;

(5) the capacity of each ship to carry equipment of deploying units; and

(6) the oceanic transport time from the selected seaport to the theater destination.

The methods applied in this research include mathematical programming and statistical tests of differences. An IP minimizes the time to outload all requirements from CONUS, similar to what military planners do when selecting ports, subject to various constraints from the problem considerations listed previously. An IP is appropriate in our case, because it can be structured to provide an unbiased means for selecting ports based on an objective criterion set, that is, the IP can mimic the port selection decisions made by military planners.

We generate random data to represent real-world fluctuations in deployment requirements, specifically the amount of equipment deploying from installations. Next, we solve the IP twice for the random deployment data. The first IP solution uses the current port selection criterion as the objective, that is, minimum inland transit time. The second IP solution uses the proposed port selection criteria as the objective, that is, minimum combined inland and oceanic transit time. Then, for each IP solution, we calculate the expected arrival time in theater of all deploying requirements. We repeat the procedure above numerous times to build a set of random instances and then we conduct a paired-samples $t$-test between the results obtained from the two IP solutions for each random instance. The statistical test provides insights about the importance of the port selection criteria considered in the associated IP objective function. Feng et al. (2012), Sanchez et al. (2011), and Murphy and Daley (1994) similarly used $t$-tests to assess the importance of various port selection criteria. The paired-samples, or repeated measures, $t$-test is appropriate in our case, because the same set of deployment requirements are measured with various treatments applied (Field, 2013). Specifically, the treatments are the two distinct objective functions considering different port selection criteria.

\section{Assumptions}

Major deployments span six or more months and the relative importance of port selection criteria changes during the deployment. Specifically, after sealift ships complete their first sailing to destination locations (usually within the first month), the ships return to the CONUS coast nearest the destination theater to onload cargo for subsequent sailings to theater (if necessary to deliver more cargo). Thus, the port selection decision is often trivial for second and later sailings, because most cargo is simply sent to the CONUS coast (east or west) nearest the destination theater. Therefore, this research focuses solely on port selection decisions for the first wave of deploying equipment. Next, real-world deployments involve moving equipment to seaports via rail and road transport modes, although rail is the preferred and dominant transport mode for large deployments (US Joint Chiefs of Staff, 2013b). Therefore, this research focuses solely on deployment requirements outloading via rail and makes no decisions about inland transport modes. Finally, this research assumes railcars are available as needed to outload equipment from installations during the first wave of deployment. This assumption is supported because the army deliberately positions its railcars at major installations to enable the rapid outloading of military equipment early in large deployments (US Joint Chiefs of Staff, 2017).

\section{Notation}

First, we provide the index sets for the IP. Let $I$ be the set of installations with a specific installation $i \in I$. Next, let $J$ be the set of seaports with a specific port $j \in J$. Also, destination
Improving the port selection process 
JDAL 5,2

theaters are represented by the set $K$ with a specific theater $k \in K$. Then, let $N$ be the set of sealift ships with a specific ship $n \in N$. Finally, deployment days are nonnegative integers represented by the set $V$ with a specific day $v \in V$.

Next, we define the parameters for the input data. Installation outload requirements for the first wave are given by $a_{i, k}$, which represents a nonnegative amount of square feet of equipment originating from installation $i$ and destined for theater $k$. In the context of seaport processing, US Headquarters of the Army (2014) defines throughput as the amount of equipment that can be processed through the node each day. Let $b_{j}$ be the daily processing rate for seaport $j$ with rates given as a nonnegative amount of unit equipment (in square feet) in a single day. Next, travel time parameters are given by $c_{i, j}$ to represent the positive integer number of days to travel by rail from installation $i$ to seaport $j$. Similarly, let $d_{j, k, n}$ represent the positive integer number of days to travel by sea from seaport $j$ to theater $k$ using ship $n$. Next, let $f_{n, j}$ be the time in days it would take for ship $n$ to reach seaport $j$ and be ready for onloading. Finally, let $g_{n}$ be the stowable cargo capacity of ship $n$ in terms of square feet of unit equipment. The output measures require additional notation, which are introduced in the Measures subsection.

\section{Integer program formulation}

The IP for the MPSP requires a single decision variable and one intermediate variable. Let $x_{i, j, n, k, v}$ be a nonnegative integer decision variable representing the square feet of equipment deploying from installation $i$ to selected port $j$ for loading onto ship $n$ destined for theater $k$ and departing the installation on day $v$. Let $y_{n, j, k}$ be a binary intermediate variable that will be used to ensure each ship $n$ is assigned to a single seaport $j$ and destined for a single theater $k$. Specifically, $y_{n, j, k}=1$ if $\operatorname{ship} n$ is assigned to seaport $j$ for onward movement to theater $k$, and $y_{n, j, k}=0$ otherwise. The objective function for the IP has two variants, each with a different minimization goal based on one or more port selection criteria, as given in equations (1a) and (1b).

$$
\begin{gathered}
\underset{i n i m i z e}{\min } \sum_{i \in I} \sum_{j \in J} \sum_{n \in N} \sum_{k \in K} \sum_{v \in V} v^{*} c_{i, j} * x_{i, j, n, k, v} \\
\operatorname{minimize} \sum_{i \in I} \sum_{j \in J} \sum_{n \in N} \sum_{k \in K} \sum_{v \in V} v *\left(c_{i, j}+d_{j, k, n}\right) * x_{i, j, n, k, v}
\end{gathered}
$$

The objective function in equation (1a) considers only the minimum Inland transit time, which most closely reflects the current port selection criterion based on habitual installation-to-port pairings. The objective function in equation (1b) considers the Combined minimum sum of Inland and Oceanic transit times, which reflects the port selection criteria proposed in this research.

The constraints for the IP are given in equations (2) through (9).

$$
\begin{array}{cc}
\sum_{j \in J} \sum_{n \in N} \sum_{v \in V} x_{i, j, n, k, v}=a_{i, k} & \forall i \in I \quad \forall k \in K \\
\sum_{i \in I} \sum_{n \in N} \sum_{k \in K} \sum_{v \in V} x_{i, j, n, k,\left(v-c_{i, j}\right)} \leq b_{j} & \forall j \in J \\
\sum_{i \in I} \sum_{j \in J} \sum_{k \in K} \sum_{v \in V} x_{i, j, n, k, v} \leq g_{n} & \forall n \in N \\
\sum_{v=1}^{f_{n, j}-c_{i, j}} x_{i, j, n, k, v}=0 & \forall i \in I \quad \forall j \in J \quad \forall n \in N \quad \forall k \in K
\end{array}
$$




$$
\begin{array}{cc}
\sum_{i \in I} \sum_{v \in V} x_{i, j, n, k, v} \leq B i g M^{*} y_{n, j, k} & \forall n \in N \quad \forall j \in J \quad \forall k \in K \\
\sum_{j \in J} \sum_{k \in K} y_{n, j, k} \leq 1 & \forall n \in N \\
x_{i, j, n, k, v} \in\left\{0 \cup \mathbb{Z}^{+}\right\} \quad \forall i \in I \quad \forall j \in J \quad \forall n \in N \quad \forall k \in K \quad \forall v \in V \\
y_{n, j, k}=\{0,1\} & \forall n \in N \quad \forall j \in J \quad \forall k \in K
\end{array}
$$

(6)
Improving the port selection process

Equation (2) ensures installation outload requirements are exactly met. Equation (3) ensures daily port processing rates are not exceeded based on the arrival day of equipment at the port, which must account for the inland transit time between installation and seaport. Equation (4) ensures ships are not overloaded with equipment. Next, equation (5) prevents equipment assignments to a specific port until the assigned ship can travel to the port. Equation (6) includes a large positive value (BigM) and sets the binary control variable based on some cargo assigned to a specific ship, seaport and theater combination. Then, equation (7) restricts each ship to onloading at no more than one seaport and destined for no more than one theater. Finally, equation (8) and equation (9) ensure the decision variables are nonnegative integer and binary, respectively.

\section{Measures}

The key measure of interest for port selection decisions is the expected arrival time of deploying military units at their theater destination (US Joint Chiefs of Staff, 2013a). Several calculations are necessary to determine this measure. First, the formulation restricts a ship to onload at a single seaport, but the ship can be loaded over time with equipment originating from any installation. As a result, the first equipment loaded onto the ship could wait several days until the last equipment is loaded onto the ship. We therefore introduce a variable $r_{n, j}$ to identify the day that $\operatorname{ship} n$ has finished onloading at its selected CONUS seaport $j$, which is based on the last day that equipment arrives. Let $r_{n, j}$ be calculated as in equation (10).

$$
r_{n, j}=\left\{\begin{array}{ll}
\max _{\left(v+c_{i, j}\right)}\left\{x_{i, j, n, k, v}\right\} & \text { if } x_{i, j ; n ; k, v}>0 \\
0 & \text { if } x_{i ; j ; n ; k, v}=0
\end{array} \quad \forall i \in I \quad \forall j \in J \quad \forall n \in N \quad \forall k \in K \quad \forall v \in V\right.
$$

Next, let $t_{i, j, n, k, v}$ be the expected theater arrival time for outload requirement $a_{i, k}$, which is routed through a single seaport $j$ for loading onto ship $n$ and having departed the installation on day $v$. We compute $t_{i, j, n, k, v}$ using equation (11).

$$
t_{i, j, n, k, v}=\left\{\begin{array}{llll}
r_{n, j}+d_{j, k, n} & \forall i \in I \quad \forall j \in J \quad \forall n \in N \quad \forall k \in K \quad \forall v \in V \mid x_{i, j, n, k, v}>0 \\
0 & \forall i \in I \quad \forall j \in J \quad \forall n \in N \quad \forall k \in K \quad \forall v \in V \mid x_{i, j, n, k, v}=0
\end{array}\right.
$$

Then, let $e_{m}^{h}$ represent the expected average time to deliver all requirements for random problem instance $m \in M$, weighted by the square feet of deploying equipment, for scenarios solved using objective function $h=\{$ Inland, Combined $\}$, as computed in equation (12).

$$
e_{m}^{h}=\left\{\begin{array}{ll}
\frac{\sum_{i \in I} \sum_{j \in I} \sum_{n \in N} \sum_{k \in K} \sum_{v \in V} T_{i, j, n, k, v}}{\sum_{i \in I} \sum_{j \in I} \sum_{n \in N} \sum_{k \in K} \sum_{v \in V} x_{i, j, n, k, v}} & \forall i \forall j \forall n \forall k \forall v \mid x_{i, j, n, k, v}>0 \\
0 & \forall i \forall j \forall n \forall k \forall v \mid x_{i, j, n, k, v}=0
\end{array} \quad \forall m \in M \quad \forall h=\{\text { Inland,Combined }\}\right.
$$


JDAL 5,2

In addition to the absolute measure $e^{h}$, a relative measure to compare the percent change in the key measure $e_{m}^{h}$ between the $h=$ Inland and $h=$ Combined port selection criteria is also useful to compare the results. Let $p_{m}$ represent the percent change between the current and proposed port selection criteria for instance $m$, as calculated in equation (13).

$$
p_{m}=\frac{e_{m}^{\text {Combined }}-e_{m}^{\text {Inland }}}{e_{m}^{\text {Inland }}} \quad \forall m \in M
$$

Finally, the proportion of equipment deploying through each CONUS coast provides useful information about which coasts are favored during port selection. Let $q$ represent a CONUS coast with $q=\{$ East, West, Gulf $\}$ and define $J^{q} \subseteq J$ with $J^{\text {East }}=\{$ Charleston, Jacksonville, Morehead City, Portsmouth $\}, J^{\text {West }}=\{$ Oakland, Port Hueneme, San Diego, Tacoma $\}$, and $J^{\text {Gulf }}=$ \{Beaumont, Gulfport\}. Then, let $s^{h}{ }_{m, q}$ be the proportion of equipment deploying in instance $m$ through a port on coast $q$ for scenario $h$, as calculated in equation (14).

$$
s_{m, q}^{h}=\frac{\sum_{i \in I} \sum_{j \in I^{q}} \sum_{n \in N} \sum_{k \in K} \sum_{v \in V} x_{i, j, n, k, v}}{\sum_{i \in I} \sum_{j \in J} \sum_{n \in N} \sum_{k \in K} \sum_{v \in V} x_{i, j, n, k, v}} \quad \forall m \in M \quad \forall q=\{\text { East, West, Gulf }\} \quad \forall h=\{\text { Inland,Combined }\}
$$

\begin{abstract}
Results
In this section, we provide empirical results from our proposed MPSP solution approach. Real-world instances of an MPSP involve transportation assets, a physical network of nodes and deployment requirements. The empirical results presented here are based on representative transportation assets and associated capabilities, a notional physical network similar to real-world deployments, and a random deployment scenario, each of which serve as input data for the IP and our subsequent analysis.
\end{abstract}

\title{
Transportation assets
}

The transportation assets for the MPSP are CONUS railcars and strategic sealift ships. As previously noted, rail is the preferred mode of transport within the CONUS. Chain tie-down flatcars are the primary railcar types used to move military trucks, tanks and other equipment to the seaport. Both government-owned and commercial-owned chain tie-down flatcars will be used during the deployment; however, government-owned railcars are positioned at major installations in sufficient quantities to ensure the first wave of deploying equipment will have immediate access to railcars to minimize delays in reaching the seaport. Thus, we do not explicitly model railcars in this research although we use representative rail transit times as described in the next subsection.

As with railcars, both government-owned and commercial-owned sealift ships will be used during a large-scale deployment. Similar to the government-owned railcars, the government-owned ships are positioned, or layberthed, near seaports and will be the primary sealift assets for the first wave of deploying units. For the present research, we assume 40 ships are available to transport the first wave of deploying equipment. Table 2 provides the ship capacities and layberth coasts used in our empirical analysis.

\section{Physical network}

The physical network includes the transportation nodes, which are the deploying installations, CONUS seaports and theater destinations. Each deployment scenario assumes a static physical network and associated deterministic transit times between nodes. First, we introduce 20 installation nodes and 10 seaport nodes in the CONUS, as 


\begin{tabular}{|c|c|c|c|c|c|c|}
\hline Ship $(n)$ & Capacity $\left(g_{n}\right)$ & Layberth coast $(q)$ & Ship $(n)$ & Capacity $\left(g_{n}\right)$ & Layberth coast $(q)$ & Improving the \\
\hline 1 & 99,290 & West & 21 & 83,146 & West & process \\
\hline 2 & 142,099 & West & 22 & 123,419 & East & \\
\hline 3 & 139,553 & Gulf & 23 & 123,419 & East & \\
\hline 4 & 139,553 & East & 24 & 123,419 & East & \\
\hline 5 & 142,099 & Gulf & 25 & 80,933 & Gulf & \\
\hline 6 & 117,137 & East & 26 & 82,521 & Gulf & 139 \\
\hline 7 & 117,137 & East & 27 & 82,521 & Gulf & \\
\hline 8 & 117,137 & East & 28 & 91,886 & Gulf & \\
\hline 9 & 117,137 & East & 29 & 91,886 & Gulf & \\
\hline 10 & 117,137 & East & 30 & 207,171 & East & \\
\hline 11 & 112,960 & East & 31 & 207,171 & East & \\
\hline 12 & 126,335 & West & 32 & 144,874 & West & \\
\hline 13 & 126,335 & West & 33 & 144,874 & East & \\
\hline 14 & 126,335 & West & 34 & 139,553 & Gulf & \\
\hline 15 & 104,066 & West & 35 & 142,099 & Gulf & \\
\hline 16 & 104,066 & West & 36 & 105,137 & Gulf & \\
\hline 17 & 104,066 & West & 37 & 105,137 & Gulf & Table 2. \\
\hline 18 & 104,066 & West & 38 & 105,137 & Gulf & Ship capacities (square \\
\hline 19 & 102,827 & Gulf & 39 & 271,363 & East & feet) and layberth \\
\hline 20 & 102,827 & Gulf & 40 & 271,363 & West & coasts \\
\hline
\end{tabular}

identified in Table 3 and shown on the CONUS map in Figure 1. The 20 installations comprise the locations that typically deploy large amounts of unit equipment during large-scale military deployments and the seaports comprise the seaports most often used during deployments. Finally, we assume two theater destinations for our empirical analysis: one across the Atlantic Ocean (called East) and one across the Pacific Ocean (called West). The specific locations of the destinations are beyond the scope of this paper.

In addition to the nodes, the network includes the transit times between nodes. Table 4 provides the inland railway transit times between each installation-port pair. Inland transit times assume an average rail speed of 22 miles per hour with trains operating $24 \mathrm{~h}$ per day, which captures expected stops and rail line interchanges consistent with rail industry standards for military unit equipment moves. Unlike railcars, which are immediately available at the installations, ships are maintained in a reduced readiness status and require several days to obtain crews and conduct sea trials prior to moving to seaports for onload operations. Table 5 gives the expected number of days for each ship to reach each CONUS seaport. Next, Table 6 provides the oceanic transit times to the East theater destination from each seaport and for each of the 40 ships and Table 7 similarly provides the oceanic transit times to the West theater destination. Finally, Table 8 gives for each seaport the coast and daily processing rates in terms of square feet of equipment processed, which includes unloading the equipment from the railcars, staging and preparing the equipment for sea transport, and loading the equipment onto the ships.

\section{Requirements}

Large-scale military deployments involve transporting equipment to both East and West theater destinations; however, one theater is the dominant theater receiving the vast majority of deploying equipment. For our empirical analysis, we assume the dominant theater receives about $85 \%$ of the deploying equipment. Furthermore, to better understand the impacts of our proposed port selection criteria, we study two deployment scenarios: a deployment with the East theater as the dominant theater (EastFlow) and a deployment with the West theater as the dominant theater (WestFlow). 


\begin{tabular}{|c|c|c|c|c|c|c|}
\hline \multirow{6}{*}{$\begin{array}{l}\text { JDAL } \\
5,2\end{array}$} & $i$ & Installation & $i$ & Installation & $j$ & Seaport \\
\hline & 1 & Fort Hood & 11 & Fort Campbell & P1 & Beaumont \\
\hline & 2 & Fort Lewis & 12 & Fort Riley & $\mathrm{P} 2$ & Gulfport \\
\hline & 3 & Camp Atterbury & 13 & Fort Drum & P3 & Charleston \\
\hline & 4 & Fort Bliss & 14 & Fort Dix & $\mathrm{P} 4$ & Jacksonville \\
\hline & 5 & Camp Pendleton & 15 & Fort Polk & P5 & Morehead City \\
\hline \multirow[t]{2}{*}{140} & 6 & Fort Stewart & 16 & Fort Sill & P6 & Portsmouth \\
\hline & 7 & Fort Bragg & 17 & Fort Irwin & P7 & Oakland \\
\hline \multirow{3}{*}{$\begin{array}{l}\text { Table } 3 \text {. } \\
\text { CONUS installation } \\
\text { and seaport nodes }\end{array}$} & 8 & Fort McCoy & 18 & Fort Knox & P8 & Port Hueneme \\
\hline & 9 & Fort Carson & 19 & Fort Leonard Wood & P9 & San Diego \\
\hline & 10 & Camp Lejeune & 20 & Camp Shelby & $\mathrm{P} 10$ & Tacoma \\
\hline
\end{tabular}

Figure 1.

Notional physical network of deploying installations and strategic seaports

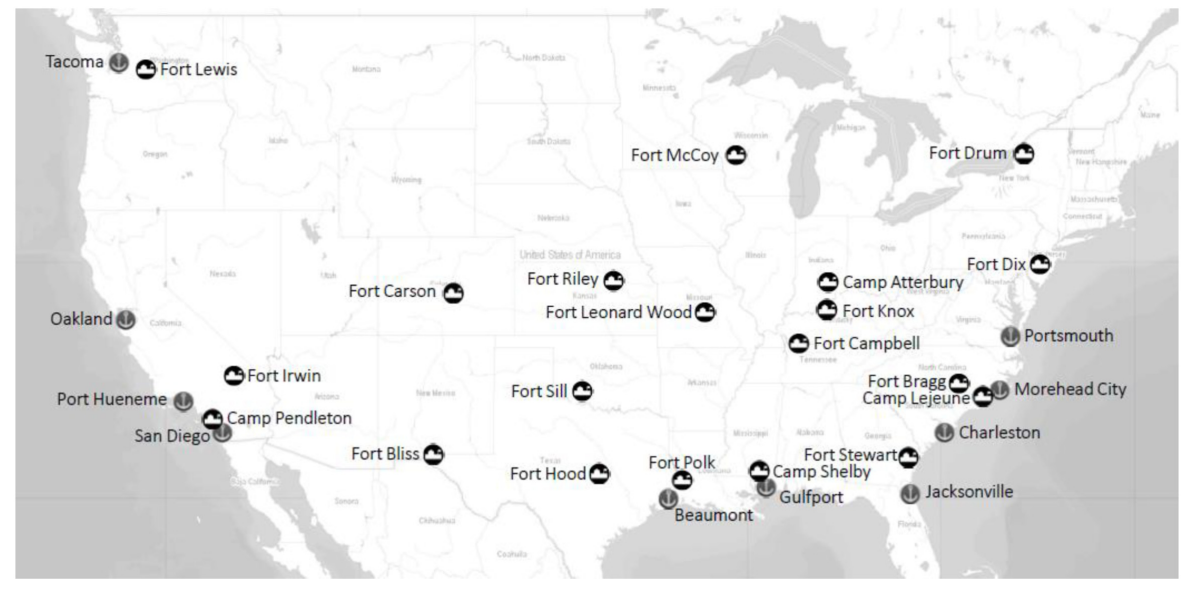

\begin{tabular}{|c|c|c|c|c|c|c|c|c|c|c|}
\hline \multirow[b]{2}{*}{ Installation (i) } & \multicolumn{10}{|c|}{ Seaport ( $i)$} \\
\hline & P1 & P2 & P3 & $\mathrm{P} 4$ & P5 & P6 & P7 & P8 & P9 & P10 \\
\hline 1 & 1 & 2 & 3 & 3 & 3 & 4 & 4 & 3 & 3 & 5 \\
\hline 2 & 5 & 6 & 7 & 6 & 7 & 6 & 2 & 3 & 3 & 1 \\
\hline 3 & 2 & 2 & 2 & 2 & 2 & 2 & 5 & 5 & 5 & 5 \\
\hline 4 & 2 & 3 & 4 & 4 & 5 & 5 & 3 & 2 & 2 & 4 \\
\hline 5 & 4 & 4 & 6 & 5 & 6 & 6 & 2 & 1 & 1 & 3 \\
\hline 6 & 2 & 2 & 1 & 1 & 1 & 2 & 6 & 6 & 6 & 6 \\
\hline 7 & 3 & 2 & 1 & 1 & 1 & 1 & 6 & 6 & 6 & 7 \\
\hline 8 & 3 & 3 & 3 & 3 & 3 & 3 & 5 & 5 & 5 & 4 \\
\hline 9 & 2 & 3 & 4 & 4 & 5 & 4 & 3 & 3 & 3 & 3 \\
\hline 10 & 3 & 2 & 1 & 2 & 1 & 1 & 7 & 6 & 6 & 7 \\
\hline 11 & 2 & 2 & 2 & 2 & 2 & 2 & 5 & 5 & 5 & 5 \\
\hline 12 & 2 & 2 & 3 & 3 & 3 & 3 & 4 & 4 & 4 & 4 \\
\hline 13 & 4 & 3 & 2 & 3 & 2 & 2 & 6 & 6 & 6 & 6 \\
\hline 14 & 3 & 3 & 2 & 2 & 2 & 1 & 6 & 6 & 6 & 6 \\
\hline 15 & 1 & 1 & 3 & 2 & 3 & 3 & 5 & 4 & 4 & 5 \\
\hline 16 & 2 & 2 & 3 & 3 & 4 & 4 & 4 & 4 & 4 & 5 \\
\hline 17 & 4 & 4 & 6 & 5 & 6 & 6 & 1 & 1 & 1 & 3 \\
\hline 18 & 2 & 2 & 2 & 2 & 2 & 2 & 5 & 5 & 5 & 5 \\
\hline 19 & 2 & 2 & 3 & 3 & 3 & 3 & 5 & 4 & 4 & 5 \\
\hline 20 & 1 & 1 & 2 & 2 & 2 & 2 & 5 & 5 & 5 & 6 \\
\hline
\end{tabular}

Table 4. $\quad 17$

Inland transit time $\quad 18$ $\left(c_{i, j}\right)$ from installation 19 $i$ to seaport $j$ 
Table 5.

Days until each ship $n$ can be available at each seaport $j$ after sailing from layberth location $\left(f_{n, j}\right)$ 
JDAL

5,2

\section{2}

Table 6.

Oceanic transit time from each seaport $j$ to the east theater ( $k=$ East) for each ship $n\left(d_{j}\right.$, East, $\left.n\right)$

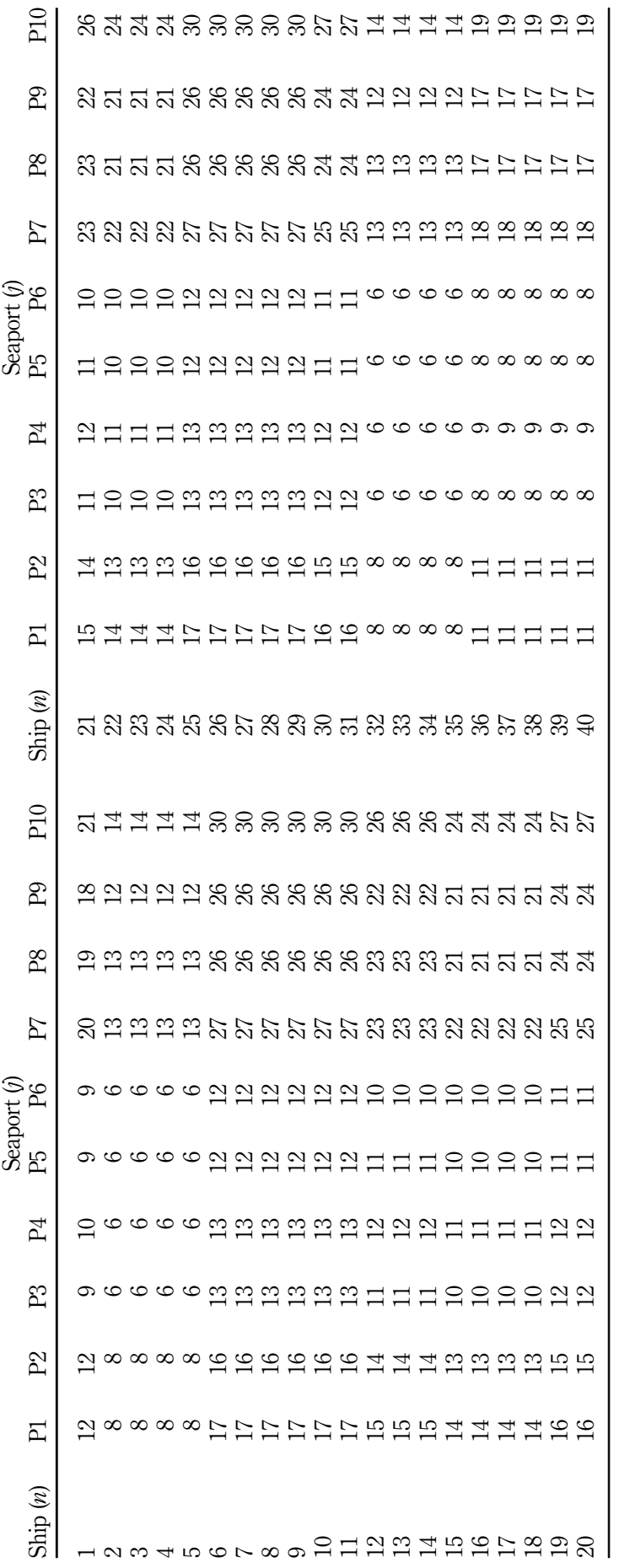

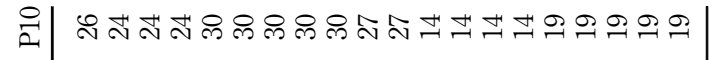

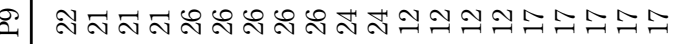

ஸีন

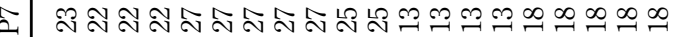

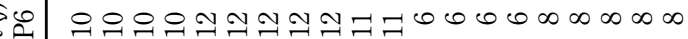

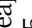


Table 7. Oceanic transit time from each seaport $j$ to the west theater ( $k=$ West) for each ship $n\left(d_{j, \text { West, } n}\right)$ 


\begin{tabular}{|c|c|c|c|}
\hline \multirow{6}{*}{$\begin{array}{l}\text { JDAL } \\
5,2\end{array}$} & Seaport $(j)$ & Coast $(q)$ & Processing rate $\left(b_{j}\right)$ \\
\hline & P1 & Gulf & 119,000 \\
\hline & P2 & Gulf & 105,000 \\
\hline & P3 & East & 109,300 \\
\hline & P4 & East & 110,000 \\
\hline & P5 & East & 88,000 \\
\hline 144 & P6 & East & 89,300 \\
\hline & P7 & West & 108,300 \\
\hline Table 8. & P8 & West & 57,300 \\
\hline Seaport coast and daily & P9 & West & 84,000 \\
\hline processing rate & P10 & West & 123,100 \\
\hline
\end{tabular}

The amount of equipment deploying from installations depends on several factors, such as the specific requirements of the military operation, the types of equipment at the installation, and the readiness of forces at the installation. For this empirical analysis, we assume each installation will outload a random amount of equipment between a medium $(\sim 175,000$ square feet) and large ( 275,000 square feet) combat support unit during the first wave and that roughly $85 \%$ of the equipment is destined for the dominant theater, as generated in equation (15).

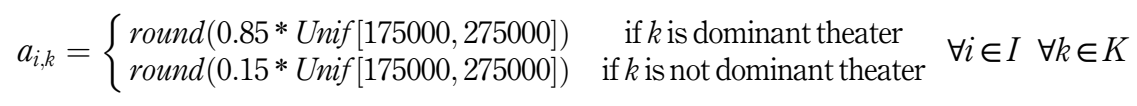

\section{IP implementation}

We implemented the IP in the General Algebraic Modeling System v24.3.3 software. All IP solutions were generated with the software's CPLEX solver to within $1.5 \%$ of optimality on a Dell Precision T7500 computer running Windows 7 with $3.33 \mathrm{GHz}$ and $48 \mathrm{~GB}$ of RAM.

\section{Empirical results: EastFlow}

This subsection reports the results for our deployment scenario with $k=$ East as the dominant theater. We generated 15 instances of the EastFlow deployment requirements and solved each instance with the IP using equation (1a) for the Inland objective function to represent the current port selection criterion and then using equation (1b) for the Combined objective function to represent the proposed port selection criteria. Table 9 provides an example of the IP results for instance $m=1$ with the expected arrival time in theater $\left(t_{i, j, n, k, v}\right)$ for each of the deployment requirements $a_{i, k}$, as calculated using equation (11). We repeated this analysis for each random instance with the summarized results provided in Table 10. The mean difference in expected average arrival times in theater was 2.36 days earlier with the Combined port selection criteria. The $95 \%$ confidence interval $(\mathrm{CI})$ around the mean difference was $(1.97,2.75)$. The paired-samples $t$-test yielded a $t$-stat of 12.93 with $14 d f$ for a $p$-value < 0.001 and Cohen's $d$ statistic just over 3. Field (2013) notes that Cohen's $d$ is an appropriate measure of effect size for the $t$-test. In addition, the average percent change in expected average arrival time in theater was about $10 \%$ earlier with the Combined port selection criteria when compared to the Inland port selection criterion. Finally, the proportion of equipment deploying through seaports on the dominant coast (East) increased from an average of 0.41 for the Inland port selection criterion to 0.47 for the Combined port selection criteria. 
Table 9.

IP solution and expected arrival time in theater using the Inland port selection criterion (EastFlow, $m=1$ ) 


\begin{tabular}{|c|c|c|c|c|c|c|}
\hline $\begin{array}{l}\text { JDAL } \\
5,2\end{array}$ & Instance $(m)$ & \multicolumn{2}{|c|}{$e_{m}^{h}$} & \multicolumn{2}{|c|}{$h=$ Inland $\quad h=$ Combined } & $p_{m}$ \\
\hline & 1 & 23.66 & 21.37 & 0.40 & 0.46 & -0.10 \\
\hline & 2 & 23.57 & 21.66 & 0.39 & 0.47 & -0.08 \\
\hline & 3 & 23.66 & 21.53 & 0.41 & 0.48 & -0.09 \\
\hline \multirow{10}{*}{146} & 4 & 25.09 & 21.71 & 0.40 & 0.46 & -0.13 \\
\hline & 5 & 23.64 & 21.69 & 0.41 & 0.45 & -0.08 \\
\hline & 6 & 24.02 & 21.83 & 0.42 & 0.47 & -0.09 \\
\hline & 7 & 22.43 & 21.63 & 0.41 & 0.46 & -0.04 \\
\hline & 8 & 24.23 & 21.59 & 0.41 & 0.47 & -0.11 \\
\hline & 9 & 23.72 & 21.83 & 0.42 & 0.45 & -0.08 \\
\hline & 10 & 24.15 & 21.74 & 0.41 & 0.46 & -0.10 \\
\hline & 11 & 24.39 & 21.76 & 0.42 & 0.48 & -0.11 \\
\hline & 12 & 23.86 & 21.71 & 0.42 & 0.47 & -0.09 \\
\hline & 13 & 25.95 & 22.07 & 0.41 & 0.46 & -0.15 \\
\hline Table 10. & 14 & 24.39 & 21.49 & 0.41 & 0.46 & -0.12 \\
\hline EastFlow results for & 15 & 23.84 & 21.64 & 0.42 & 0.49 & -0.09 \\
\hline 15 random instances & Averages & 24.04 & 21.68 & 0.41 & 0.47 & -0.10 \\
\hline
\end{tabular}

Empirical results: WestFlow

This subsection gives the results for the deployment scenario with $k=$ West as the dominant theater. As with the EastFlow analysis, we generated 15 instances of the WestFlow deployment requirements and solved each instance with the IP using equation (1a) for the Inland solutions and then using equation (1b) for the Combined solutions. Table 11 provides a summary of the solution results. The mean difference in expected average arrival times in theater was 3.85 days earlier with the Combined port selection criteria. The $95 \%$ CI around the mean difference was $(3.45,4.25)$. The paired-samples $t$-test yielded a $t$-stat of 20.85 with $14 d f$ for a $p$-value $<0.001$ and Cohen's $d$ statistic just over 6 . In addition, the average percent change in expected average arrival time in theater was about $13 \%$ earlier with the Combined

port selection criteria when compared to the Inland port selection criterion. Finally, the

\begin{tabular}{lccccc}
\hline & \multicolumn{5}{c}{$s^{h}{ }_{m, \text { East }}$} \\
Instance $(m)$ & $h=$ Inland & $e^{h}{ }_{m} h=$ Combined & $h=$ Inland & $h=$ Combined & $p_{m}$ \\
\hline 1 & 29.04 & 25.17 & 0.34 & 0.45 & -0.13 \\
2 & 30.38 & 25.24 & 0.33 & 0.44 & -0.17 \\
3 & 29.24 & 25.98 & 0.30 & 0.45 & -0.11 \\
4 & 28.73 & 26.11 & 0.33 & 0.41 & -0.09 \\
5 & 29.11 & 25.23 & 0.32 & 0.45 & -0.13 \\
6 & 29.16 & 25.28 & 0.34 & 0.45 & -0.13 \\
7 & 29.90 & 25.85 & 0.34 & 0.44 & -0.14 \\
8 & 28.78 & 25.96 & 0.33 & 0.42 & -0.10 \\
9 & 28.99 & 25.53 & 0.33 & 0.43 & -0.12 \\
10 & 29.91 & 25.7 & 0.33 & 0.43 & -0.14 \\
11 & 29.80 & 25.43 & 0.33 & 0.41 & -0.15 \\
12 & 30.51 & 26.12 & 0.33 & 0.42 & -0.14 \\
13 & 30.23 & 25.74 & 0.32 & 0.44 & -0.15 \\
14 & 28.72 & 25.84 & 0.33 & 0.43 & -0.10 \\
15 & 30.19 & 25.76 & 0.33 & 0.43 & -0.15 \\
Averages & 29.51 & 25.66 & 0.33 & 0.43 & -0.13 \\
& & & & &
\end{tabular}

Table 11.

WestFlow results for 15 random instances 
proportion of equipment deploying through seaports on the dominant coast (West) increased from an average of 0.33 for the Inland port selection criterion to 0.43 for the Combined port selection criteria.

\section{Discussion}

For the EastFlow deployment scenario, the expected average arrival times in theater achieved when selecting ports using the proposed criteria of the combined inland and oceanic time were statistically different than the current criterion of inland transit times (Inland vs Combined in Table 10). The mean difference in expected average arrive time in theater of about 2.4 days earlier (roughly a 10\% reduction) was significant at the 0.001 alpha level across the 15 random instances. In addition, the associated mean difference had a large effect size with a Cohen's $d$ of about 3.

Similarly, for the WestFlow deployment scenario we achieved generally consistent results with the EastFlow scenario. The expected average arrival times in theater when selecting ports using the proposed criteria of the combined inland and oceanic time were statistically different than the current criterion of inland transit times (Inland vs Combined in Table 11). The mean difference in expected average arrival time in theater of about 3.9 days earlier (roughly a $13 \%$ reduction) was significant at the 0.001 alpha level across the 15 random instances. Also, the associated mean difference had a large effect size with a Cohen's $d$ of about 6 .

Several important results emerge from our empirical analysis. First, in both the EastFlow and WestFlow scenarios, the earliest expected average arrival times to theater destinations were obtained with the proposed port selection criteria and, more importantly, the mean differences were statistically significant at the 0.001 level with relatively large effect sizes. Second, the mean differences in expected average arrival times were most pronounced in the WestFlow scenario with absolute and relative improvements in expected average arrival times of 3.9 days and $13 \%$, respectively. Third, the proportional shift of equipment deploying through seaports nearest the dominant theater were similarly larger in the WestFlow scenario with the proportions through West coast seaports increasing from 0.33 to 0.43 . Further, despite some equipment shifting to the dominant coast, a substantial proportion of deploying cargo still deployed through habitual ports. Fourth, port congestion was evident in the solutions with seaport throughputs constrained early at each seaport for both the EastFlow and WestFlow scenarios. As an example, Table 12 shows constrained port congestion for the WestFlow scenario $(m=1)$ early in the deployment at each seaport for both the Inland and Combined port selection criteria. More importantly, the port congestion was extended at seaports nearest the dominant theater (West) when using the Combined criteria, because a higher proportion of equipment flows through the seaports nearest the dominant theater. Specifically, seaports P7 (Oakland), P8 (Port Hueneme), P9 (San Diego) and P10 (Tacoma) had equipment arriving later in the Combined solution compared to the Inland solution. Although the proposed port selection criteria resulted in equipment arriving to CONUS seaports later when compared to the current criterion, the deploying equipment arrived earlier to theater destinations.

Although our research provides no new insights into port selection methods, our empirical results align well with previous researchers in several respects. First, we found that both inland and oceanic transit times should be considered when selecting ports for military deployments. This result is not widely known to military planners who select seaports during deployments, primarily because military doctrine, as referenced in this paper, suggests that the best seaports to use are generally those closest to deploying units for the first wave of deployers. The empirical analysis presented herein suggests that our proposed port selection criteria align with those of other researchers who noted that both inland and seaside factors
Improving the port selection process 
JDAL

5,2

148

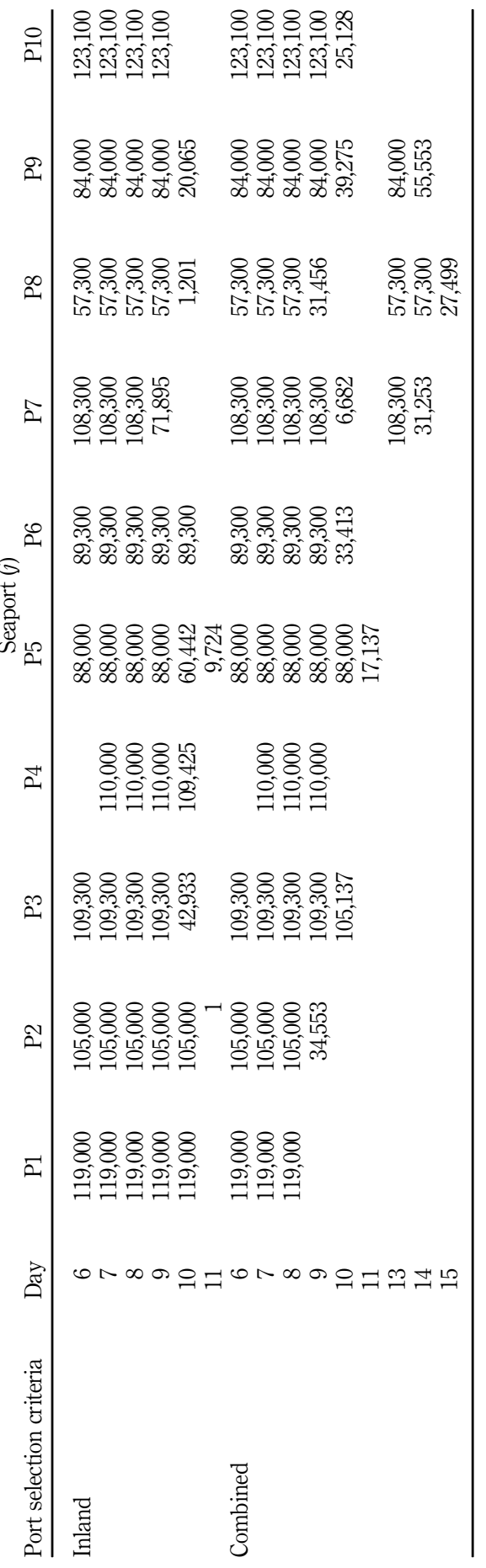

Table 12

Port throughputs by day for Inland vs Combined port selections (WestFlow; $m=1$ ) 
were important when selecting ports, including Jiang et al. (2020), Kramberger et al. (2018), Moya and Valero (2017), Yuen et al. (2012), Tran (2011), Tongzon (2009), and Malchow and Kanafani (2004). More specifically, our finding that inland and oceanic transit time considerations yield the best outcome are most similar to those of Moya and Valero (2017), who suggested that port selection must balance inland factors with factors capturing ports located on or near main shipping routes.

\section{Conclusion}

The primary decision of the MPSP is the assignment of each deploying unit to a seaport during the military deployment. The goal is the earliest expected time of arrival for units at theater destinations. The current port selection method, which is based on habitual installation-port pairings, for the first wave of deploying equipment is based on the premise that faster CONUS outloads are achieved by assigning units to ships that are strategically positioned nearest their habitual port. The present research, however, suggests that these habitual pairings should be de-emphasized and instead, the combined inland and oceanic transit times should be considered to improve the speed of delivery to theater. Our research adds the military deployer's perspective to the broader perspective of shippers, in particular those of large shippers. Specifically, we suggest that the perspective of military deployers, who tend to favor delivery speed over other considerations, is a viable variant of port selection problems. Finally, the methods and associated results presented in this paper provide support for our proposed port selection criteria, which should be considered by US Transportation Command planners when assigning units to ports during major deployment operations in the future.

\section{Future work}

Future work on the MPSP might incorporate delays that could arise due to military units being unfamiliar with seaports other than their habitual port. Additionally, future researchers might include additional port selection criteria besides the inland and oceanic transit times assessed in this paper. Such criteria may come from the perspectives of shipping companies (e.g. rail or truck companies for inland moves and RORO operators for sea moves) and port authorities or operators (e.g. seaports owned by commercial entities). Next, the present work assumed deterministic transit times and seaport capacities to simplify the solution approach. In large-scale military deployments, few inputs are known with certainty. Specifically, large-scale military deployments are exceedingly rare, so the key elements of the deployment system are not routinely operating at stressed or constrained levels. Therefore, future work to extend the MPSP could incorporate random elements of operational problems, such as varying inland transit times due to railway congestion, varying oceanic transit times due to different ship speeds, and fluctuating seaport throughput capacities due to labor disputes or equipment breakages. In addition, researchers might also consider other modes of transport in CONUS instead of rail. Specifically, mode choice could be another decision of the model as considered by Wu et al. (2014) in the context of port choice and Abate et al. (2019) in the context of inland freight choice. Finally, the MPSP could include an objective to minimize the number of seaports used because operationally a seaport assigned only a relatively small amount of cargo should remain closed with the cargo diverted to, and subsequently processed by, a nearby seaport.

\section{References}

Abate, M., Vierth, I., Karlsson, R., de Jong, G. and Baak, J. (2019), "A disaggregate stochastic freight transport model for Sweden”, Transportation, Vol. 46 No. 3, pp. 671-696.

Improving the port selection process 
JDAL 5,2

Baert, L. and Reynaerts, J. (2020), "An examination of the determinants of inter-port competition for US imports”, Case Studies on Transport Policy, Vol. 8 No. 2, pp. 281-292.

Fan, L., Wilson, W.W. and Dahl, B. (2012), "Congestion, port expansion and spatial competition for US container imports", Transportation Research Part E, Vol. 48, pp. 1121-1136.

Feng, M., Mangan, J. and Lalwani, C. (2012), "Comparing port performance: western European versus Eastern Asian ports", International Journal of Physical Distribution and Logistics Management, Vol. 42 No. 5, pp. 490-512.

Field, A. (2013), Discovering Statistics Using IBM SPSS Statistics, 4th ed., Sage Publishing, Thousand Oaks, CA.

Hales, D., Lam, J.S.L. and Change, Y.-T. (2016), "The balanced theory of port competitiveness", Transportation Journal, Vol. 55 No. 2, pp. 168-189.

Hsu, W.K.K., Lian, S.J. and Huang, S.H.S. (2020), "An assessment model based on a hybrid MCDM approach for the port choice of liner carriers", Research in Transportation Business and Management, Vol. 34, p. 100426.

Jiang, X., Fan, H., Luo, M. and Xu, Z. (2020), "Strategic port competition in multimodal network development considering shippers' choice”, Transport Policy, Vol. 90, pp. 68-89.

Kaliszewski, A., Kozlowski, A., Dabrowski, J. and Klimek, H. (2020), "Key factors of container port competitiveness: a global shipping lines perspective”, Marine Policy, Vol. 117, 103896.

Kolar, P. and Rodrigue, J.-P. (2018), "Container port selection by freight forwarders in Central and Eastern Europe hinterland: the case of the Czech Republic", Nase More, Vol. 65 No. 3, pp. 1-7.

Kramberger, T., Intihar, M., Vanelslander, T. and Vizinger, T. (2018), "On distance decay in port choice", Technical Gazette, Vol. 25 No. 5, pp. 1314-1320.

Malchow, M.B. and Kanafani, A. (2004), “A disaggregate analysis of port selection”, Transportation Research Part E, Vol. 40, pp. 317-337.

Maloni, M. and Jackson, E.C. (2005), "North American container port capacity: an exploratory analysis", Transportation Journal, Vol. 44 No. 3, pp. 1-22.

Moya, J.M. and Valero, M.F. (2017), "Port choice in container market: a literature review", Transport Reviews, Vol. 37 No. 3, pp. 300-321.

Murphy, P.R. and Daley, J.M. (1994), “A comparative analysis of port selection factors”, Transportation Journal, Vol. 34 No. 1, pp. 15-21.

Murphy, P.R., Daley, J.M. and Dalenberg, D.R. (1992), "Port selection criteria: an application of a transportation research framework", Logistics and Transportation Review, Vol. 28 No. 3, pp. 237-255.

Osundiran, O.A., Okonta, F. and Quainoo, H. (2020), "An examination of port choice indicators and critical transportation parameters as a basis for port selection", Journal of Maritime and Transportation Sciences, Vol. 58 No. 1, pp. 9-24.

Parola, F., Risitano, M., Ferretti, M. and Panetti, E. (2017), "The drivers of port competitiveness: a critical review”, Transport Reviews, Vol. 37 No. 1, pp. 116-138.

Sanchez, R.J., Ng, A.K.Y. and Garcia-Alonso, L. (2011), "Port selection factors and attractiveness: the service providers' perspective”, Transportation Journal, Vol. 50 No. 2, pp. 141-161.

Sayareh, J. and Alizmini, H.R. (2014), "A hybrid decision-making model for selecting container seaport in the Persian Gulf", The Asian Journal of Shipping and Logistics, Vol. 30 No. 1, pp. 75-95.

SDDCTEA Pamphlet 700-2 (2011), Logistics Handbook for Strategic Mobility Planning, Scott AFB, Illinois, Vol. 10.

Steven, A.B. and Corsi, T.M. (2012), "Choosing a port: an analysis of containerized imports into the US”, Transportation Research Part E, Vol. 48, pp. 881-895.

Tang, L.C., Low, J.M.W. and Lam, S.W. (2011), "Understanding port choice behavior - a network perspective”, Networks and Spatial Economics, Vol. 11, pp. 65-82. 
Tongzon, J.L. (2009), "Port choice and freight forwarders", Transportation Research Part E, Vol. 45, pp. 186-195.

Tran, K. (2011), "Studying port selection on liner routes: an approach from logistics perspective", Research in Transportation Economics, Vol. 32, pp. 39-53.

US Department of Transportation (2021), "The ready reserve force", available at: https:/www. maritime.dot.gov/national-defense-reserve-fleet/ndrf/maritime-administration $\% \mathrm{E} 2 \% 80 \% 99 \mathrm{~s}$ ready-reserve-force.

US Government Accountability Office (2005), Actions Needed to Improve the Availability of Critical Items during Current and Future Operations (GAO-05-275), United States Government, WA, DC.

US Headquarters of the Army (2014), "Army techniques publication 4-0.1", Army Theater Distribution, Vol. 10.

US Headquarters of the Army (2015), "Army techniques publication 3-35", Army Deployment and Redeployment, Vol. 3.

US Joint Chiefs of Staff (1996), “Joint publication 4-01.2”, Joint Tactics, Techniques, and Procedures for Sealift Support to Joint Operations, Vol. 10.

US Joint Chiefs of Staff (2013a), “Joint publication 3-35”, Deployment and Redeployment Operations, Vol. 1.

US Joint Chiefs of Staff (2013b), "Joint publication 4-09", Distribution Operations, Vol. 12.

US Joint Chiefs of Staff (2017), "Joint publication 4-01”, The Defense Transportation System, Vol. 7.

Wu, Y., Liu, J. and Peng, C. (2014), "Analysis of port and inland transport mode selection", in 2014 11th International Conference on Service Systems and Service Management (ICSSSM), pp. 1-6.

Yuen, C.A., Zhang, A. and Cheung, W. (2012), "Port competitiveness from the users' perspective: an analysis of major container ports in China and its neighboring countries", Research in Transportation Economics, Vol. 35, pp. 34-40.

\section{Corresponding author}

Dave C. Longhorn can be contacted at: david.c.longhorn.civ@mail.mil
Improving the port selection process 